\title{
Catalunya, actor en la cooperació transfronterera: quinze anys de perspectiva, processos i resultats*
}

\author{
Javier Martín-Uceda
}

Universitat de Girona. Departament de Geografia javier.martin@udg.edu

Rebut: gener de 2018

Acceptat: febrer de 2018

Publicat: juliol de 2018

\section{Resum}

Aquest article vol donar una perspectiva sobre el paper que ha tingut la Generalitat de Catalunya com a actor en matèria de cooperació transfronterera. L'anàlisi es basa en dos elements: per un costat, els projectes finançats pel fons INTERREG en les convocatòries III i IV (1999-2014), en què Catalunya ha participat com a actor; i per altre, les estructures de cooperació que ha impulsat i desenvolupat també durant els mateixos anys. L'estudi posa de manifest com especialment durant els anys 2003-2006 hi va haver un impuls destacat del conjunt d'iniciatives transfrontereres, tant en projectes finançats per INTERREG com en iniciatives de cooperació institucional. Quant als resultats, pel que fa als projectes en els quals participa Catalunya amb altres actors, fomenten especialment el desenvolupament econòmic i la gestió del medi ambient; i pel que fa a la cooperació institucional, tot i que han reeixit algunes iniciatives, calen encara esforços perquè es consolidi.

Paraules clau: cooperació transfronterera; INTERREG; Catalunya; regió

Resumen. Cataluña, actor en la cooperación transfronteriza: quince años de perspectiva, procesos y resultados

Este artículo quiere presentar una perspectiva sobre el papel que ha tenido la Generalitat de Catalunya como actor en materia de cooperación transfronteriza. El análisis se basa en dos elementos: por un lado, los proyectos financiados por el fondo INTERREG en las

* Aquest article s'emmarca en un projecte de recerca encarregat per la Fundació Catalunya Europa, dins del Programa Llegat Pasqual Maragall. En concret, una recerca sobre Pasqual Maragall i la cooperació territorial encarregada a l'autor i feta entre els anys 20017-2018. 
convocatorias III y IV (1999-2014), en los que Cataluña ha tomado parte; y por otra, las estructuras de cooperación que ha impulsado y desarrollado también durante estos mismos años. El estudio pone de manifiesto cómo especialmente durante los años 2003-2006 hubo un fuerte impulso al conjunto de iniciativas transfronterizas, tanto en proyectos financiados por INTERREG como con iniciativas de cooperación institucional. En cuanto a los resultados, por lo que se refiere a los proyectos en los que participa Catalunya con otros actores, fomentan especialmente el desarrollo económico y la gestión del medio ambiente; y por lo que se refiere a la cooperación institucional, aunque se han conseguido algunas iniciativas, hacen falta aún esfuerzos para consolidarse.

Palabras clave: cooperación transfronteriza; INTERREG; Cataluña; región

Résumé. La Catalogne, acteur de la coopération transfrontalière : quinze ans de perspectives, de processus et de résultats

Cet article vise à donner un point de vue sur le rôle joué par la Generalitat de la Catalogne en tant qu'acteur de la coopération transfrontalière. L'analyse repose sur deux éléments : d'une part les projets financés par les fonds INTERREG dans les appels III et IV (19992014), où la Catalogne a pris part en tant qu'acteur; et d'autre part, les structures de coopération qu'elle a promues et développées au cours des mêmes années. L'étude montre que c'est notamment pendant les années 2003-2006 qu'il y a eu un essor remarquable de l'ensemble d'initiatives de coopération transfrontalière, à la fois dans les projets financés par INTERREG et dans les initiatives de coopération institutionnelle. En ce qui concerne les résultats, nous mettons en évidence que les projets où la Catalogne participe avec d'autres acteurs favorisent plus particulièrement le développement économique et la gestion environnementale. Quant à la coopération institutionnelle, même si certaines initiatives ont réussi, des efforts sont encore nécessaires pour sa consolidation.

Mots-clés: coopération transfrontalière; INTERREG; Catalogne; région

Abstract. Catalonia, an actor in cross-border cooperation: Fifteen years of perspective, processes and results

This article examines the role of the Government of Catalonia as a cross-border actor. The analysis is based on two elements: projects financed by the INTERREG fund in periods III and IV (1999-2014) in which Catalonia took part, and cooperation structures that were developed in the same period. The analysis brings to light the significant development of cross-border cooperation initiatives during the period 2003-2006 through both INTERREG funded projects and institutional cooperation structures. The results reveal that most projects in which Catalonia has taken part are related to economic development and environment management and although some institutional cooperation initiatives have been successful, further effort is required to consolidate them.

Keywords: cross-border cooperation; INTERREG; Catalonia; region

\section{Sumari}

1. La cooperació transfronterera a la Unió Europea: una realitat consolidada

2. Catalunya i la cooperació transfronterera
3. Conclusions

Referències bibliogràfiques 


\section{La cooperació transfronterera a la Unió Europea: una realitat consolidada}

Aquest article té com a objectiu principal descriure quina ha estat l'evolució de les estratègies que ha desenvolupat Catalunya com a regió pel que fa a cooperació transfronterera. Diferents estratègies que són resultat, com vol posar de manifest el text, de diferents visions i concepcions del territori, no només europeu, sinó també català. Un debat llarg que dura fins als nostres dies, i que suposa també una reflexió sobre com s'articula Catalunya i com ho fa amb el seu entorn. En primer lloc, s'aporta un marc evolutiu sobre la cooperació transfronterera a Europa, així com les competències sobre la cooperació que té Catalunya segons el seu Estatut. A continuació, el debat sobre les diferents estratègies polítiques abans esmentat, $\mathrm{i}$ pròpiament un repàs a les diferents iniciatives i la participació de Catalunya en projectes concrets finançats per INTERREG. Per últim, un apartat de conclusions.

La cooperació transfronterera en el si de la Unió Europea és un fet consolidat després de més de seixanta anys des dels primers acords de cooperació (Medeiros, 2011; Perkmann, 2003). Els anys posteriors a la Segona Guerra Mundial representen el moment de naixement de la cooperació transfronterera a Europa. Autors com Domínguez (2008) posen de manifest el paper dels ens locals en aquesta primera etapa, lluny encara de la consolidació plena amb la posada en funcionament de la iniciativa INTERREG l'any 1990. El mateix Domínguez (2008) defineix aquesta fase com a "prehistòria» de la cooperació.

També Oliveras, Durà i Perkmann (2010) situen aquests primers acords voluntaris entre actors locals com el primer pas per consolidar la cooperació transfronterera. Els autors, en el seu article, en defineixen quatre etapes.

La primera, des dels anys cinquanta fins a inicis dels vuitanta, destaca per la creació de la considerada primera euroregió l’any 1958, anomenada EUREGIO, a la frontera entre Alemanya i els Països Baixos, i d'altres acords en aquesta mateixa àrea geogràfica, al BENELUX o a la frontera entre Suïssa, França i Alemanya (Perkmann, 1999). Els acords es basaven en la voluntat dels diferents actors, en especial locals o regionals, que entraven en una política centrada fins al moment en els estats.

La segona fase s'inicia amb els primers reglaments jurídics creats per impulsar i regular la cooperació transfronterera. El primer el Conveni de Madrid, de l'any 1980, titulat «Conveni marc europeu de cooperació transfronterera entre autoritats i comunitats territorials», sota auspici del Consell d'Europa. Segons els mateixos autors, altres documents com la "Carta europea d'autonomia local», del 1985, ajuden també a impulsar la cooperació transfronterera.

Una tercera fase, caracteritzada per la consolidació i l'expansió de la cooperació transfronterera per l'aplicació dels diferents acords anteriors, però també per la política regional europea. L'aprovació dels fons INTERREG, orientats precisament al foment dels projectes de cooperació transfronterera, transnacional i interregional. La necessitat de gestionar els recursos i d'impulsar els projectes propicia de manera notable l'establiment d'estructures de coope- 
ració, com les euroregions o d'altres iniciatives similars i a múltiples escales de treball. Aquest moment també coincideix amb l'emergència en el conjunt de la Unió Europea de visions sobre com s'ha d'articular el conjunt del territori. És un debat que discuteix el paper de les regions i de les ciutats a Europa, i com aquestes entitats podrien tenir una major rellevància en la presa de decisions en l'engranatge comunitari. Aquestes discussions, en què prendran part Jordi Pujol i Pasqual Maragall, portaran per exemple a la creació del Comitè de les Regions l'any 1994, així com associacions de regions i municipis, que voldran esdevenir portaveus de les necessitats i les problemàtiques davant les institucions europees ${ }^{1}$.

Per últim, els autors inauguren una nova etapa, que correspon amb l'actualitat, i que coincideix amb l'aprovació per part del Parlament Europeu de les Agrupacions Europees de Cooperació Territorial (AECT), figura dotada de personalitat jurídica que té com a objectiu facilitar i fomentar la cooperació territorial per reforçar la cohesió econòmica i social.

Després del Tractat de Lisboa del 2007, la cohesió territorial passa a ser un objectiu reconegut per la Unió Europea i, per tant, una prioritat per a les polítiques regionals. És el tercer pilar de la política de cooperació, juntament amb els objectius de convergència i competitivitat. Per tant, la cooperació territorial no és simplement un element necessari per consolidar el mercat comú, sinó també necessari per a un territori integrat socialment i econòmicament. I aquest fet dóna a les regions frontereres un paper d'actors polítics necessaris per aconseguir aquests objectius (Wassenberg et al., 2015).

\section{Catalunya i la cooperació transfronterera}

Després de l'entrada de l'estat espanyol a la Unió Europea, Catalunya, com les altres comunitats autònomes ${ }^{2}$ (Beltrán, 2007), ha pogut desenvolupar polítiques de cooperació transfronterera amb els altres territoris de l'altre costat de la frontera sota el paraigua que suposen les polítiques comunitàries. Per al cas català, la cooperació s'ha desenvolupat amb actors i territoris francesos $\mathrm{i}$ d'Andorra.

La cooperació transfronterera no només es porta a terme per auspici de les polítiques europees, ja que els diferents actors han impulsat iniciatives més enllà d'aquestes. Aquest fet és un exemple de la complexitat i la diversitat de processos que es poden generar en la cooperació territorial i transfronterera, fruit de les moltes escales de treball que es produeixen i la transversalitat i la multiplicitat d'actors que hi poden prendre part: tots els nivells administratius,

1. En aquest context, s'inicien un gran nombre d'associacions entre ciutats i regions amb diferents objectius i temàtiques. Per exemple, de regions frontereres, marítimes, o més diverses per tractar temes com la sostenibilitat, la innovació o la gestió urbana, entre molts altres. La seva voluntat serà la mobilització d'actors per defensar els interessos de cada xarxa davant institucions superiors, especialment les europees.

2. «Convenio-marco europeo sobre cooperación transfronteriza entre comunidades o autoridades territoriales», 21 de maig de 1980, BOE 16 d'octubre de 1990. (08/10/2017). 
locals, supralocals i regionals, i actors de diferents àmbits, administracions públiques, universitats, cambres de comerç o d'altres.

L'anàlisi que es presenta a continuació té en compte el paper de Catalunya, en concret de la Generalitat de Catalunya, com a actor en la cooperació transfronterera al llarg dels darrers quinze anys, deixant de banda la resta de projectes realitzats per ajuntaments, consells comarcals, províncies o altres. Es vol posar èmfasi en les xarxes que s'estableixen, la capacitat de lideratge en els projectes i la tipologia de projectes realitzats, a partir de l'anàlisi de les convocatòries INTERREG III i IV (1999-2006/2007-2013). Però la cooperació transfronterera va més enllà dels projectes realitzats amb els fons europeus, tal com s'ha mencionat anteriorment. Així, es pot analitzar també la participació dels actors en xarxes temàtiques que treballin en un àmbit de cooperació concret, com el desenvolupament econòmic, la gestió del medi ambient o d'altres. Per tant, aquest serà el segon àmbit d'anàlisi, la participació de la Generalitat de Catalunya com a actor en diferents estructures de cooperació i la geopolítica que se'n desprèn del desplegament de les diferents accions.

\subsection{Les competències en matèria de cooperació territorial}

La Generalitat de Catalunya té capacitat per participar com a actor en cooperació transfronterera, si bé algunes competències són de l'estat espanyol. Així, l'Estatut d'Autonomia de Catalunya recull en el seu article 197 sobre cooperació transfronterera, interregional i al desenvolupament, que ${ }^{3}$ :

1. «La Generalitat ha de promoure la cooperació amb les regions europees amb què comparteix interessos econòmics, socials, ambientals i culturals, $\mathrm{i}$ hi ha d'establir les relacions que corresponguin».

2. «La Generalitat ha de promoure la cooperació amb altres territoris, en els termes que estableix l'apartat 1».

És, per tant, un objectiu per a Catalunya impulsar la cooperació transfronterera. Tanmateix, la cooperació i l'establiment d'acords amb altres entitats territorials per part de Catalunya i les altres administracions territorials quedà regulada per diferents tractats, acords i convenis que signà l'estat espanyol, competent pel que fa a l'establiment de tractats internacionals. L'estat espanyol va signar el 1980 el Conveni de Madrid, que va entrar en vigor l'any 1990 després de ser ratificat. Emparat per aquest tractat, Espanya ha subscrit dos tractats internacionals que regulen la cooperació transfronterera ${ }^{4}$ : el Tractat de Baiona, amb França, vigent des de 1997; i el de València, amb Portugal, vigent en aquest cas des de 2004.

3. Estatut d'Autonomia de Catalunya de 2006. Parlament de Catalunya. <https://www.parlament.cat/document/cataleg/48089.pdf> [consulta: 10 d'octubre de 2017].

4. La cooperación transfronteriza realizada por las entidades territoriales españolas. Ministeri d'Administracions Públiques, 2016. [consulta: 5 d'octubre de 2017]. 
El Tractat de Baiona ${ }^{5}$ recull que tots els territoris i els actors territorials de les comunitats autònomes del País Basc, Navarra, Aragó i Catalunya poden emprendre accions de cooperació transfronterera quan l'objecte d'aquesta cooperació sigui en un àmbit competencial de cada entitat territorial.

Per un altre costat, els estats membres defineixen els procediments per aprovar les AECT entre els seus agents territorials i els estats amb els quals s'han de firmar els acords de cooperació. Així, per al cas d'Espanya, són les diferents entitats territorials les que proposen els acords que volen establir, així com el seu reglament i funcionament. Es remeten a l'estat central i és aquest el qui ha de donar el vistiplau, després d'intercanviar la informació amb l'estat central francès.

\subsection{Les visions de Catalunya, les visions de la cooperació territorial}

En els darrers anys la cooperació transfronterera ha estat una eina de treball per a diferents administracions públiques catalanes per consolidar les relacions amb altres entitats territorials franceses. Una activitat que ha generat diferents accions i polítiques que han estat en alguns casos divergents. Això és fruit de les diverses visions que han tingut els responsables polítics catalans a diferents nivells, en especial a l'hora de dirigir el govern de la Generalitat per la seva visió i concepció de Catalunya, cosa que ha determinat també l'acció política de cada actor.

La cooperació transfronterera catalana es fa a diferents escales, ja que tots els actors hi poden prendre part. La feta per la Generalitat té una escala regional, i s'han impulsat iniciatives de gran abast com la participació a la Comunitat de Treball dels Pirineus. Les accions impulsades per les administracions locals tenen, generalment, també una escala local, si bé hi ha una excepció: les impulsades per Barcelona. Per a l'entitat de la capital catalana, les seves accions tenen una repercussió que va molt més enllà de la política local, i que poden significar un complement a les realitzades per la Generalitat o, fins i tot, rivalitzar-hi. Bon exemple d'aquest fet és l'activitat transfronterera i europea desplegada des d'inicis dels anys noranta, i coincidint temporalment amb la presidència de Jordi Pujol a la Generalitat de Catalunya, i de Pasqual Maragall a l'alcaldia de Barcelona. Ambdós líders aposten per dues visions sobre la cooperació territorial, que vol dir dues propostes d'Europa. Aquesta dualitat és fruit de dues visions també enfrontades sobre l'articulació de Catalunya i la seva organització territorial (Pradel-Miquel, 2016; Tomás, 2017).

Francesc Morata (2006), quan exposa les dues propostes de Maragall i de Pujol en referència a Europa, els descriu com a emprenedors polítics, que despleguen els seus recursos amb l'objectiu d'aconseguir, mitjançant la cooperació amb altres actors, el canvi institucional que propugnen en les estructures socials. L'autor descriu les dues visions, afirmant que la de Jordi Pujol, que presidí l'Associació de Regions d'Europa (ARE) durant el període 1992-1996,

5. Tractat de Baiona, 1997. Boletín Oficial del Estado. (05/10/2017) 
és l'Europa de les regions, i gira en torn a la capacitat de les regions de cohesionar les seves societats i projectar-se en l'espai europeu. A Catalunya, aquest fet lliga amb el nacionalisme de Pujol, amb la voluntat de cohesionar la societat catalana sota la idea de la nació, amb elements com la cultura o la llengua: una Catalunya-nació que es projecta cap a Europa i en busca el reconeixement. Les xarxes público-privades i la mobilització d’interessos són la prioritat de la seva acció, per situar Catalunya entre les regions més dinàmiques del continent. Europa ha de servir, per tant, per reafirmar Catalunya i el seu paper entre les regions. Cal esmentar la Catalunya Nord, com a territori d'especial interès per a l'acció exterior de Pujol. L'acció de la Generalitat en llengua i cultura catalanes esdevindrà un factor fonamental per mantenir aquesta cultura als territoris francesos nord-catalans, i per aquest motiu l'obertura de la Casa de la Generalitat l'any 2003 tindrà un gran simbolisme.

En canvi, la visió de Pasqual Maragall, alcalde de Barcelona entre el 1982 i 1997, es desenvolupa a partir de ciutats, una proposta possiblement més funcionalista, que deixa de banda el nacionalisme identitari. Presidí el Consell de Municipis i Regions d'Europa (CMRE) durant el període 1991-1997, i defensà una Europa on la prioritat és la seva articulació, on les ciutats i els territoris tenen un paper clau en aquest procés. A més, això permetrà realment la consolidació d'una ciutadania europea, que cregui en el projecte comú i treballi per avançar en la integració europea. D’aquí, l'aposta per les xarxes de ciutats transfrontereres i la seva voluntat d'apostar per una visió estratègica, defensant el principi de subsidiarietat. Rebutja per tant la idea de la Catalunya-nació, que per definició suposa limitar el territori d'aquesta nació, i mira cap a la concepció oberta que suposa una Europa en xarxa, on s'assoleixi la mencionada ciutadania europea per sobre dels nacionalismes.

En aquest punt s'ha de recuperar una part de l'esmentat en el primer apartat, sobre el debat de l'Europa de les regions i ciutats entre els anys vuitanta i noranta del segle passat. Una Europa de les regions en la qual Pujol se sentirà còmode perquè és una visió que pot servir a les regions més avançades econòmicament per reclamar les seves demandes, especialment econòmiques; però que també serveixi per reconèixer les particularitats culturals i identitàries d'algunes regions europees. Algunes, després del fracàs d'aquesta Europa de les regions, han apostat per altres vies per reivindicar els seus interessos. Per altra banda, una altra aposta, l'Europa de les ciutats, defensada per Maragall, recull les aportacions fetes per geògrafs com Roger Brunet, que exposa la realitat territorial europea com una xarxa de ciutats connectades entre elles, que es complementen i competeixen, i que són les que realment articulen el territori. Aquesta visió també entronca amb d'altres treballs que posen de relleu com les ciutats tenen el poder de decisió en assumptes com l'economia, tal com defensen altres autors com Saskia Sassen o posteriorment Richard Florida.

Aquestes dues apostes per Europa mostren també les dues visions d'articulació del territori de Catalunya abans esmentades: un debat sobre l'encaix de Barcelona i la seva àrea metropolitana amb el conjunt de Catalunya (Nel.lo, 
2013; Tomás, 2017). Un conflicte en què hi haurà dues propostes oposades que responen als dos poders polítics imperants a Catalunya des de la democràcia i fins a mitjans dels anys 2000, el govern de centre-dreta al govern regional $i$ el govern municipal de Barcelona en mans del partit socialista.

Aquestes dues visions no responen exactament, o no només, a la cooperació transfronterera, però sí que tenen un impacte en el resultat de la seva acció governamental. I per tant, en el paper de Catalunya com a actor en les xarxes de cooperació. Les dues institucions, Generalitat i Ajuntament de Barcelona, han impulsat diferents iniciatives de cooperació que han tingut diversos recorreguts al llarg del temps, així com diferents resultats. L'alcalde Maragall impulsà la xarxa C6 de ciutats, formada per Palma, València, Saragossa, Tolosa, Montpeller i Barcelona. L'espai d'influència d'aquestes ciutats és el que ell anomenà macroregió, «el nord del sud». També la Comissió Interpirinenca de Poders Locals (CIPL), que agrupa Barcelona i la Seu d'Urgell amb Tolosa i altres petites ciutats franceses i andorranes. Durant el govern Pujol, destaca la creació dels Quatre Motors d'Europa ${ }^{6}$, si bé no és una xarxa de cooperació transfronterera, sinó interregional. I l'Euroregió Mediterrània, formada per Catalunya, Llenguadoc-Rosselló i Migdia-Pirineus, aquesta sí, xarxa de cooperació transfronterera. Aquesta Euroregió restà activa del 1991 al 1998; però la seva activitat fou escassa, derivada d'alguns projectes INTERREG però sense poder implicar-hi un major nombre d'actors a diverses escales territorials (Morata, 2005). És interessant remarcar altre cop, com a exemple d'aquestes dues visions i tensió, que gairebé van coincidir en el temps les dues presidències de l'ARE i el CMRE de Pujol i Maragall respectivament durant els anys noranta, des d'on impulsaven les seves dues estratègies per Europa i Barcelona.

L'arribada del govern d'esquerres a la Generalitat de Catalunya al 2003, presidit per Pasqual Maragall, suposa un canvi pel que fa a les iniciatives de cooperació transfronterera. El mateix acord de govern, el conegut com Pacte del Tinell ${ }^{7}$, recull propostes per avançar en matèria de cooperació transfronterera. I el pacte recull els següents punts referents a la cooperació transfronterera:

— «Establir acords internacionals amb altres entitats polítiques sobre matèries de competència de la Generalitat, especialment pel que fa a la col-laboració transfronterera».

— «Promoure la coordinació de polítiques econòmiques, socials i culturals en el conjunt dels territoris del denominat "arc mediterrani" en el marc de la UE, avançant vers la construcció d'Euroregió Pirineus-Mediterrània”.

- "Catalunya pot d'esdevenir un nucli essencial d'una regió europea que comprèn l'espai de l'antiga Corona d'Aragó i s'estén fins a Montpeller i

6. Quatre Motors d'Europa. Associació formada per les regions de Catalunya, Llombardia, Roine-Alps i Baden-Württemberg, per col-laborar en diversos àmbits d'interès mutu.

7. Acord per a un govern catalanista i d'esquerres a la Generalitat de Catalunya, 2003. <http://www.ub.edu/OGC/Catalunya_VII_leg_Tinell.pdf>. (05/10/2017) 
Tolosa. Una euroregió que s'estén per l'eix Mediterrani, per l'eix de l'Ebre, i que connecta la Mediterrània occidental amb el nucli d'Europa, amb el nord d'Itàlia i amb el Magrib».

— «Consolidar l'euroregió de l'arc mediterrani».

Una vocació transfronterera que tenia com a principal objectiu la creació i la consolidació d'una euroregió on Catalunya tingués un paper motor, com a espai de cooperació per impulsar el desenvolupament econòmic, les infraestructures i la millora de la influència a les institucions europees.

En els darrers anys, a partir del 2010, el govern de CiU i el govern de Junts pel Sí han donat un altre rumb a la cooperació transfronterera. Si bé s'ha mantingut la feina realitzada amb l'Euroregió Pirineus-Mediterrània, s'han produït canvis estructurals que han suposat el desplaçament de les oficines de l'Euroregió a Perpinyà, i la pèrdua d'una de les seus que s'establia a Barcelona. Per un altre costat, no s'ha intentat cap més desplegament de noves iniciatives de cooperació, si bé s'han anat renovant els convenis de cooperació amb el Consell Departamental dels Pirineus Orientals. Si s'analitza el programa electoral de Junts pel Sí, coalició de govern actual (2017), no s'esmenta ni una sola vegada la cooperació transfronterera ni l'euroregió. En canvi, s'aposta de manera decidida per ampliar ràpidament les delegacions de Catalunya a l'exterior per actuar diplomàticament amb els estats. Hi ha un canvi d'estratègies i d'orientacions, que pot significar la convicció que Catalunya ha d'actuar com un nou estat, posant en un altre nivell la cooperació amb altres regions. Els estats cooperen amb els estats, i si Catalunya ja no és una regió, deixa en part aquesta feina amb altres regions europees.

\subsection{La participació de Catalunya en estructures de cooperació transfronterera}

La cooperació transfronterera es desenvolupa a diferents escales i amb multitud d'agents territorials, tal com s'ha mencionat anteriorment. En aquest apartat s'analitzaran les estructures i les xarxes transfrontereres on la Generalitat ha pres part en els darrers quinze anys.

\section{L'Euroregió Pirineus-Mediterrània}

En tots aquests anys destaca la creació de l'Euroregió Pirineus-Mediterrània. La idea d'una euroregió no era nova, ja que sota la presidència de Jordi Pujol es va constituir l'Euroregió Mediterrània, tot i que el seu èxit fou limitat, com ja s'ha exposat. Aquesta idea, proposada per Pasqual Maragall, tenia la complicitat de líders francesos, en especial d'alcaldes, com el de Perpinyà, Jean Paul Alduy, o de Georges Frêche, històric alcalde de Montpeller i que l'any 2004 era president de la regió del Llenguadoc-Rosselló. Corresponia als territoris les capitals dels quals formaven la xarxa C-6. Aquest fet serà una realitat, amb l'excepció de la Comunitat Valenciana. Hi participaran, per tant, l'Aragó, les Illes Balears, el Llenguadoc-Rosselló, el Migdia-Pirineus i Catalunya. Per raons polítiques, el president de la comunitat, Francisco Camps, del Partit 
Popular, estimà que no era convenient formar part d'aquesta xarxa, impulsada per Pasqual Maragall com a president de la Generalitat. Els arguments van ser que no era part de l'estratègia de desenvolupament de la seva regió, i que a més situava "València en la periferia de Barcelona». Apostava, en canvi, per un altre eix, dit "de la Prosperitat»" ${ }^{8}$, amb la Comunitat de Madrid i les Illes Balears. En realitat, però, hi ha un conflicte geopolític important: l'impuls de l'Euroregió per part de Pasqual Maragall, del Partit Socialista, suposa una confrontació amb la idea de l'Espanya radial del Partit Popular i que s'ha consolidat en l'Espanya dels darrers decennis (Bel, 2013). Francisco Camps, amb la presidenta Esperança Aguirre, van voler limitar un possible potenciament de l'Eix Mediterrani, que avancés cap a una Espanya multipolar, trencant així el model centralista que havia consolidat el Partit Popular durant el govern Aznar, en especial en aspectes com les infraestructures.

A diferència d'altres organismes de cooperació, com la Comunitat de Treball dels Pirineus, l'Euroregió té un caràcter de governança horitzontal i vertical, en cooperació entre actors a múltiples escales. La declaració fundacional ${ }^{9}(2004)$ diu que «Amb la participació activa d'organismes de la societat civil que representen els nostres ciutadans i dels governs locals i supralocals, cercarem els ajuts i les complicitats europeus i estatals necessaris per garantir l'èxit de la nova Euroregió Pirineus-Mediterrània». Té, doncs, una vocació oberta i flexible, ja que pretén involucrar a tots els actors, locals, regionals, estatals i europeus, en la cooperació. A més d'involucrar-hi igualment actors privats, més enllà de l'administració pública.

Tot i que l'Euroregió no té una figura jurídica, es va apostar per aprovar una AECT. Els representants de les regions de l'Euroregió, amb l'excepció de l'Aragó, que havia abandonat la participació en l'Euroregió ${ }^{10}$, l'any 2007 aprovaren la declaració constitutiva de l'AECT. El conveni final serà signat l'any 2009 a Palma.

Els estatuts de l'AECT, a partir de la seva creació, recollien l'establiment de la direcció a Tolosa, la secretaria general a Barcelona i una representació a Brussel.les. Aquesta estructura, però, s'ha transformat recentment, amb canvis en l'organigrama organitzatiu i el desplaçament de totes les seus a Perpinyà.

\section{La Comunitat de Treball dels Pirineus}

La Comunitat de Treball dels Pirineus es fundà l'any 1982, per part de totes les regions espanyoles i franceses dels dos costats dels Pirineus i Andorra, amb la voluntat de tractar els problemes compartits que es podien tenir en aquest espai, en especial els territoris de muntanya. Un espai que nasqué i treballà

8. Camps y Aguirre reivindicaran el «eje de la Prosperidad» frente al de Zapatero-Maragall. ABC. 11/06/2004. <http://www.abc.es/hemeroteca/historico-11-06-2004/abc/Nacional/camps-y-aguirre-reivindicaran-el-eje-de-la-prosperidad-frente-al-de-zapatero-maragall_9621962313196.html>.

9. Declaració constitutiva de l'Euroregió Pirineus Mediterrània. 29/10/2004. [Consulta el 14 de novembre de 2017]. <http://www.euroregio.eu/sites/default/files/041029_declaracio_constitutiva_epm_cat.pdf>.

10. L'Aragó abandona la participació a l'Euroregió l'any 2006, com a protesta pel conflicte judicial amb Catalunya respecte a les obres d'art religiós de la Franja de Ponent. 
durant més de vint anys sense cap instrument legal que permetés tenir una estructura pròpia, amb les limitacions que significa.

El seu funcionament suposa que la direcció de l'entitat, que recau en la secretaria general, sigui rotatòria entre les diferents regions. L'any 2005, amb la presidència per a Catalunya, i sota el seu impuls, la Comunitat de Treball dels Pirineus passà a tenir una entitat pròpia. Així, per primer cop, tenia entitat jurídica, en forma de consorci, i podia actuar de manera autònoma, amb un pressupost i interactuar directament amb la Unió Europea. Gràcies a aquest fet pogué tenir la responsabilitat d'assumir la gestió del Programa Operatiu de Cooperació Transfronterera entre Espanya, França i Andorra (POCTEFA), encarregat d'assumir els fons INTERREG per a la cooperació transfronterera.

\section{L'Hospital Transfronterer de la Cerdanya i l'Eurodistricte de l'Espai Català Transfronterer}

Destaquen dues iniciatives que, tot i que el seu impacte territorial no és per al conjunt de Catalunya, la Generalitat hi ha jugat un paper primordial. Primer, l'Hospital Transfronterer de la Cerdanya, ja una realitat i en ple funcionament; i en segon lloc, l'intent d'impulsar l'Eurodistricte de l'Espai Català Transfronterer.

Pel que fa a l'Hospital Transfronterer, després de diferents intents per aprofundir en la cooperació sanitària, l'any 2003 un estudi de viabilitat econòmica finançat per INTERREG III suposa la primera pedra per construir el primer hospital transfronterer d'Europa a Puigcerdà, que donarà servei al conjunt de la Cerdanya. La Generalitat de Catalunya, juntament amb la Fundació Hospital Transfronterer de la Cerdanya, constituïda per impulsar i gestionar l'Hospital amb actors dels dos costats de la frontera, aconseguí 18 milions d'euros del POCTEFA 2007-13 per construir-lo (Berzi, 2013). El paper de la Generalitat de Catalunya en aquesta construcció és un exemple de capacitació del nivell regional per exercir com a actor transfronterer. La Generalitat assumí la responsabilitat del govern espanyol, dialogant directament amb el govern central francès. El Ministeri de Sanitat espanyol cedí a Catalunya les gestions.

Per un altre costat, un altre exemple és l'Eurodistricte de l'Espai Català Transfronterer. L'any 2007 un grup d'autoritats locals i regionals signà a Ceret ${ }^{11}$ un manifest per iniciar els tràmits necessaris per constituir un Eurodistricte, amb el suport de la Generalitat de Catalunya, per l'espai format entre la província de Girona i el departament francès dels Pirineus Orientals, amb una AECT com a figura jurídica de gestió. Havia de servir per consolidar la seva complementarietat social i econòmica, i impulsar les polítiques necessàries per superar el fet fronterer.

L'Eurodistricte, però, no s'ha desenvolupat, ja que encara no s'ha aprovat la seva constitució deu anys després de la firma de la Declaració de Ceret. Segons Castañer i Feliu (2012), els canvis polítics en els governs locals i regionals, les diferents posicions davant la prioritat o no de reivindicar la catalanitat dels

11. Declaració d'Intenció per crear un Eurodistricte de l'Espai Català Transfronterer. 2007. Ceret. $<$ http://www.eurodistricte.cat/sites/default/files/contingut/declaracio_ceret_0.pdf>. 
territoris francesos, la prioritat d'altres temes en moments de crisi econòmica, la dilació en el temps de la signatura dels estatuts per part del govern francès i la falta de lideratge han contribuït a la desmotivació i a la falta de capacitat d'acció conjunta i coordinada.

A partir del 2010, amb el darrer govern de CiU i el govern de Junts pel Sí, no s'ha impulsat cap nou projecte d'estructura de cooperació transfronterera. Si bé s'ha continuat amb l'Euroregió, no s'ha consolidat l'Eurodistricte i no sembla que hi hagi cap possibilitat a curt termini. S'ha mencionat anteriorment, però sembla que l'estratègia d'internacionalització de la Generalitat ha apostat per altres espais de cooperació, en especial per mitjà d'oficines de representació en d'altres estats. La situació política de Catalunya ha influït en aquest canvi d'orientació i de polítiques de la Generalitat.

\subsection{Catalunya i la iniciativa INTERREG: líder $i$ actor de projectes transfronterers}

Després de la participació en xarxes de cooperació transfronterera, un altre element que serveix per comprovar l'activitat transfronterera d'una regió europea com Catalunya és estudiar els seus projectes de cooperació. Dels projectes, se'n pot analitzar el líder i el conjunt d'actors, la seva tipologia, la durada, el pressupost, entre d'altres ítems. L'anàlisi que es farà a continuació utilitza la metodologia emprada pel grup de recerca APTA, de la Universitat de Girona. Exposada en diversos articles (Feliu et al., 2013), permet l'estudi dels projectes finançats per INTERREG en diferents convocatòries, a través de diferents variables: tipologia de projectes, actors, territoris implicats i recursos gestionats.

Amb aquesta metodologia s'ha fet una anàlisi dels programes III i IV d'INTERREG del Programa Operatiu Espanya-França-Andorra (POCTEFA), entre els anys 2000-2006 i 2007-2013, respectivament. Per a aquest article només s'han tingut en compte els projectes en els quals participen actors regionals, deixant de banda els locals o provincials; els que en terminologia d'estadística europea diríem NUTS II, i en concret per a Catalunya, ES51. Observant les dades, més de la meitat dels projectes estan liderats per autoritats locals, i les regions són el segon nivell administratiu que lidera més projectes.

Catalunya va ser la segona regió que va liderar més projectes durant el INTERREG III, amb 11, precedida per Navarra, amb 20; però seguida a molta distància per Aragó, amb 3. En canvi, per a INTERREG IV, Catalunya, tot $\mathrm{i}$ liderar un projecte menys, passà a ser la regió que encapçalava un major nombre de projectes, en aquest cas seguida per Navarra. Aquestes són les dues regions amb més capacitat de liderar projectes a la frontera. Aquest fet pot respondre a la voluntat política d'implicar-se en la cooperació transfronterera de les seves administracions, i de la capacitat tècnica, administrativa i financera que suposa liderar i participar en un projecte europeu de cooperació transfronterera.

Per al cas del conjunt d'actors, és la segona regió amb més actors, després de Navarra (46), però seguida molt de prop pel País Basc (41) o l'Aragó (39) 
Taula 1. Nombre de projectes liderats per actors regionals catalans (III, IV, V INTERREG-A)

\begin{tabular}{ccc}
\hline INTERREG III (1999-2006) & INTERREG IV (2007-2013) & INTERREG V* (2014-2020) \\
\hline 11 & 10 & 3 \\
\hline
\end{tabular}

* Fins a la segona convocatòria, 2017.

Font: POCTEFA.

Taula 2. Nombre de projectes participats per actors regionals catalans (III, IV, V INTERREG-A)

\begin{tabular}{ccc}
\hline INTERREG III (1999-2006) & INTERREG IV (2007-2013) & INTERREG V* (2014-2020) \\
\hline 43 & 38 & 14 \\
\hline
\end{tabular}

* Fins a la segona convocatòria, 2017.

Font: POCTEFA.

durant el III període. El mateix passa durant el IV, en què Catalunya també és la segona regió amb més actors, $i$ en la qual torna a liderar el rànquing Navarra. De l'anàlisi dels actors és important destacar el fet que gairebé tots els actors són públics; per tant, de la Generalitat de Catalunya, ja sigui directament per conselleries com per agències públiques com el Centre Tecnològic Forestal de Catalunya o l'Institut de Recerca i Tecnologies Agroalimentàries.

Si només analitzem, com s'ha mencionat anteriorment, els projectes de caire regional, Catalunya no destaca més que les altres regions, tot i ser molt més gran en extensió i població. Cal tenir en compte, però, les característiques de Navarra i el País Basc, en especial per la seva capacitat fiscal, i en el cas de Navarra, el fet de ser una comunitat uniprovincial. Aquesta última assumeix totes les competències que la resta de regions es reparteixen amb les províncies. Però, per altra banda, la seva capacitat fiscal també pot facilitar la decisió d'invertir més recursos en aquests projectes. Aquestes comunitats poden tenir una major capacitat d'impulsar projectes gràcies a aquestes característiques.

\section{Conclusions}

La tasca de Catalunya, i en concret de la Generalitat, com a actor en la cooperació transfronterera en el seu àmbit d'actuació ha estat diversa al llarg dels anys. Certament, l'impuls que hi donen els fons europeus és important, potser fonamental; però més enllà, hi ha també altres aspectes. Per un costat, l'impuls personal, i per un altre, la geopolítica. Després de parlar amb actors implicats i assistir a debats sobre la temàtica, se'n desprèn aquest fet, que massa projectes o intents per impulsar cooperació transfronterera, ja siguin projectes o estructures, depenen de la visió o voluntat d'una persona amb capacitat de decisió o d'influir.

Les dues visions de Jordi Pujol i de Pasqual Maragall reflecteixen bé aquest fet. I mostren la falta d'una visió de país, que superi els programes del partit governant. Per una altra banda, la geopolítica derivada de les diferents actuacions polítiques dels governants. La voluntat de fer de Catalunya un actor en 
la cooperació transfronterera i internacional és fruit de la mateixa dinàmica interna catalana, sense deixar el context global en el qual s'emmarca.

Un altre aspecte que s'ha de valorar és el referit a les competències en cooperació. Aquestes han permès impulsar nombroses iniciatives, si bé el govern de l'Estat continua tenint l'última paraula. Davant el debat que alguns autors com Harguindéguy i Bray (2009) aporten sobre si la cooperació pot augmentar la capacitat d'actuació de les regions, certament amb instruments com l'AECT es facilita aquet fet; però els estats són els que han de donar el vistiplau. Precisament, Keating (2008) apunta que, tot i la regionalització de polítiques europees com aquesta, es pot generar un procés centralitzador. Durant els anys vuitanta la idea de l'Europa de les Regions emergia amb força, en especial pel desplegament dels fons estructurals i de cohesió, i podia generar un possible reforçament del nivell regional davant dels estats. Però el mateix Keating (2008) afirma que uns decennis després s'ha demostrat que aquest debat no s'ha desenvolupat, i que els estats, tot i la seva transformació i la integració europea no han deixat de ser els actors clau que formen la Unió Europea. La diversitat de situacions dins dels estats membres i la complexitat derivada de les diferències entre cada territori fa impensable que en un futur proper s'estableixi una veritable Europa de les Regions.

En tot cas, la feina realitzada durant aquests anys per la Generalitat demostra un desequilibri en funció dels objectius polítics dels governants, especialment visible a l'hora d'analitzar les estructures de cooperació. Pel que fa a I'INTERREG, Catalunya com a regió no destaca per sobre de les altres, si bé és cert que les dades de l'estudi plantegen que en la frontera hispano-francesa la gran part dels projectes són participats majoritàriament per actors locals. La capacitat de Catalunya sembla per tant encara per desplegar en bona mesura. Per una altra banda, la voluntat política de fer de Catalunya un actor transfronterer potent, i que la cooperació sigui un element transversal en els diferents nivells d'actuació política, necessita d'una consolidació que respongui a una acció política clara i determinada en aquesta direcció durant un temps més perllongat.

\section{Referències bibliogràfiques}

BeL, G. (2013). España, capital París. Barcelona: Destino.

BELTRÁN, S. (2007). «La cooperación transfronteriza e interterritorial». Revista d'Estudis Autonòmics i Federals, 4, 215-246.

BerZI, M. (2013). «Cross-border cooperation and local development in the Pyrenees. The Case of Cerdanya». European Journal of Geography, 4 (4), 47-60.

CASTAÑER, M. i FeLiU, J. (2012). «L'Eurodistricte català transfronterer. Un espai emergent sense marc administratiu». Treballs de la Societat Catalana de Geografia, 74, 41-58. <https://doi.org/10.2436/20.3002.01.12>

DOMíNGUEZ, L. (2008). «Quelques considérations sur les origines de la coopération transfrontalière en Europe : 1950-1980». RECERC. Revista Electrònica del Centre de Recerca d'Estudis Catalans. 
Euroregió Pirineus Mediterrània (2004). «L'Euroregió, un futur compartit». Declaració fundacional de l'Euroregió Pirineus Mediterrània.

Feliu, J.; Berzi, M.; Vicente, J.; Castañer, M. i Llussà, R. (2013). «Análisis de los proyectos y actores transfronterizos España-Francia en el período 2007-2013». Geographicalia, 63-64, 75-93.

HarguindéguY, J. i Bray, Z. (2009). "Does cross-border co-operation empower European regions? The Case of Interreg III-A France-Spain». Environment and Planning C: Government and Policy, 27, 747-760. $<$ https://doi.org/10.1068/c08119>

KEATING, M. (2008). «A quarter century of the Europe of the regions». Regional and Federal Studies, 18 (5), 629-635. $<$ https://doi.org/10.1080/13597560802351630>

Medeiros, E. (2011). "(Re)defining the Euroregion Concept». European Planning Studies, 19 (1), 141-158. <https://doi.org/10.1080/09654313.2011.531920>

Morata, F. (2005). Conclusions del seminari: Les Euroregions: Experiències i aprenentatges per a l'Euroregió Pirineus-Mediterrània. Institut Universitari d'Estudis Europeus.

- (ed.). (2006). 20 anys de Catalunya a la Unió Europea. Patronat Català Pro Europa.

NeL.LO, O. (2013). «Barcelona y Cataluña: las raíces sobre el debate del policentrismo del sistema urbano catalán». Ciudad y Territorio, XLV (176).

Oliveras, X.; DurÀ, A. i PERKMANN, M. (2010). «Las regiones transfronterizas: balance de la regionalización de la cooperación transfronteriza en Europa (1958-2007)». Documents d'Anàlisi Geogràfica, 56 (1), 21-40.

PERKMANN, M. (1999). «Building governance institutions across European borders». Regional Studies, 33 (7), 657-667. <https://doi.org/10.1080/00343409950078693>

- (2003). «The rise of the Euroregion. A bird's eye perspective on European cross-border co-operation». Department of Sociology. Lancaster University. Lancaster.

Pradel-Miquel, M. (2016). Catalunya, xarxa de ciutats. Barcelona: Fundació Catalunya Europa.

TOMÁs, M. (2017). Governar la Barcelona real. Pasqual Maragall i el dret a la ciutat metropolitana. Barcelona: Fundació Catalunya Europa.

Wassenberg, B.; Reitel, B.; Peyrony, J. i Rubió, J. (2015). Territorial Cooperation in Europe - A Historical Perspective. Luxemburg: Comisión Europea. $<$ https://doi.org/10.2776/374386 > 